\section{THE PRACTICAL APPRECIATION OF EMOTIONAL GLUCOSURIA}

FREDERICK S. HAMMETT, PH.D.

Professor of Physiology, College of Physicians and Surgeons, Medical Department of the University of Southern California

LOS ANGELES

In 1911, Cannon, Shohl and Wright ${ }^{1}$ demonstrated that a glucosuria was produced in animals as the result of emotional excitement which takes the form of pain, fear or rage. These results have since been confirmed by the work of Scott, ${ }^{2}$ Rolly and Oppermann, ${ }^{3}$ Jacobson $^{4}$ and others.

That emotional excitement in man also tends to a glucosuria, at times permanent, at times transitory, is evidenced from the clinical reports of Kleen, ${ }^{5} \mathrm{Naunyn}^{3}$ and others.

Such pathologic conditions as mania or mental disturbances are also often accompanied by presence of sugar in the urine, as reported by Schultze. ${ }^{\top}$ He considers that the evidence supports the view that the amount of sugar eliminated is somehow connected with the degree of depression, and is also increased with the fear-psychoses. Raimann ${ }^{9}$ and also Mita ${ }^{9}$ have arlded to this fund of clinical evidence the fact that melancholia is very often accompanied by glucosuria. The most detailed study was made by Folin and Denis ${ }^{10}$ on the inmates of an institution for the insane. They found that 12 per cent. of the 192 subjects under investigation had glucosuria. In addition, Arndt ${ }^{11}$ studied several cases of delirium induced by alcohol and noted the development of glucosuria with the progress of the mental incoordination.

It is, accordingly, obvious that disturbance of psychic entity is often accompanied by the presence of sugar in the urine, and the so-called "sugar-center" of Bernard is thus intimately connected with the higher centers of thought and imagination.

The question now is, Does ordinary disturbance of mental equilibrium, such as is aroused in every person by various external circumstances, tend toward the production of a glucosuria?

There is ample evidence that relatively normal causes of emotional excitement may lead to an excretion of sugar in the urine. Smillic, ${ }^{1:}$ working with medical students undergoing written examination, found that four out of nine developed a glucosuria as the result of a hard examination, while but one of the nine did this after an easy examination. Fiske and Carnon ${ }^{13}$ found glucosuria development in twelve out of twenty-five members of a football squad after an important contest, five of whom were substitutes, not participants. The urine of the only spectator examined contained sugar. Folin, Denis and Smillie,"1) investigating the effects of examinations on students, found that six out of thirty-three medical students, or 18 per cent., developed glucosuria as the result of the examination, and that six out of thirty-six women

1. Cannon, Shohl and Wright: Cited from Cannon: Bodily Changes in Pain, Fear, Hunger and Rage, 1915, p. 70.

2. Scott: An, Jour. Physiol, 1914, xxxiv, 283

3. Rolly and Oppermann: Biocliem. Ztschr., 1913, xlix, 201

4. Yacobson: Biochem. Ztschr., 1913, li, 449.

5. Kleen: On Diabetes Mellitus and Glycosuria, Philadelphia, 1900 pp. 22,37 .

6. Naunyn: Der Diabetes Mellitus, Vienna, 1898, pp. 72, 73

7. Schultze: Verhand1. d. Ges, deutsch. Naturforscl. und Aerzle,

1908, ii, 358

8. Ramann: Ztschr. f. Nervenh., 1902, xxiii, Abt. iii, 14, 19.

8. Raimann: Ztschr. f. Nervenh., 1902, xxiii, Abt. iii, 14, 19

10. Molin, Denis and Smillie: Jour. Biol. Chem., 1914, xvii, 519.

10. Folin, Denis and Smilie: Jour. Biol. Chem

11. Arndt: Ztschr. f. Nervenh., 1897, $x$,

13. Fiske and Cannon: Compare Footnote 1, p. 75 students, or 17 per cent., showed a similar facility for excreting sugar as the result of mental strain.

In order to extend and confirm these results, I carried out, with the assistance of one of my students, Mr. E. E. Kessler, and the instructor in physiology, Mr. J. Larson, a series of experiments wherein the exciting stimuli were purely emotional in character but of different types.

The first type of stimulus was the effect of participation in a decisive football game. It was found that nine out of the seventeen subjects examined, or 53 per cent., developed a glucosuria.

The second type of disturbance was the effect of watching the game with potentiality of participation. Six of the seven substitutes examined, or 85 per cent.. developed glucosuria.

The third type of excitement was observation of the game with disinterestedness as to participation. Six of the thirteen spectators, or 46 per cent., had developed a glucosuria.

The fourth and last type of stimulus studied was a short but difficult written examination given to first year medical students. Eleven of the twenty-scven urines examined, or 43 per cent., showed the presence of stgat after the test.

These results are much higher than those obtained by the workers previously quoted. Every subject reported on in our experiments failed to show the presence of sugar in the urine before the experiments.

The cumulative evidence herein cited denotes conclusively that emotional excitation of widely varying types tends toward a production of glucosuria. May it not be true that the thorough physical examination of patients, which to the physician is a routine, may be and often is an ordeal to the patient, and that as the result of the mental condition thus aroused, either through fear or anxiety, a glucosuria ma develop, thus leading to a diagnosis of a condition which does not exist? That this occurs in many instances I sincerely believe. Accordingly, physicians in general should recognize this potential condition, and not rely on positive sugar tests found in urines obtained following such examination, but should obtain a sample of urine at some later date when excitation, due to changed and unaccustomed procedure, has had opportunity to die down and disappear.

The practical point now in evidence is to determine the extent of this emotional glucosuria as to the time factor. Is it of brief or long duration, and how soon after excitation does it disappear? To determine this point, we examined the urines of the eleven students who had developed glucosuria as the result of the examination, four hours after the excitation, and found that at this time only one of the cleven still showed the presence of reducing sugar. In this case the relative amount was considerably diminished.

From the latter work, it is demonstrated that emotional glucosuria is but transitory in nature and soon disappears after removal of the exciting cause, bearings out in full the foregoing contention.

High Tuberculosis Mortality Among Negroes.-Following is the number of deaths and the death rate, from tuberculosis. for the white and for the negro races, respectively, in New York City for the year 1915 . White race: pulmonary tuberculosis: deaths, 8,279 ; rate, 1.54 ; tuberculosis, all forms: deaths, 9.595 ; rate, 1.79 ; all causes: deaths, 73,512 ; rate, 13.71 . Colored race: pulmonary tuberculosis: deaths, 546 ; rate, 5.20 ; tuberculosis, all forms: deaths, 654; rate, 6.23; all catuses: deaths, 2.681 ; rate, 25.53.-Bull. N. Y. Dcpt. of Health. 